\title{
Adölesan Voleybol Oyuncularında Core Stabilizasyon Egzersizlerinin Smaç Hızına Etkisi*
}

\author{
Kerem YILDIRIM***, Umut BEYCAN***, Tahsin BEYZADEOĞLU ${ }^{* * * * *}$
}

$\ddot{O} \mathbf{z}$

Amaç: Bu çalışma, adölesan voleybol oyuncularında düzenli core stabilizasyon egzersizlerinin smaç hızına etkisinin araştırılması amacı ile gerçekleştirilmiştir.

Yöntem: Çalışmaya 15-18 yaş aralığında, aynı spor kulübünde profesyonel voleybol oynayan toplam 60 sporcu gönüllü olarak katılmıştır. 30 sporcudan oluşan deney grubunun smaç hızı radar tabanca ile ölçüldükten sonra sporcular core stabilizasyon egzersizi programına alınarak 6 haftalık çalışma sonunda smaç hızları tekrar ölçülmüştür. Yine 30 sporcudan oluşan kontrol grubunun ise smaç hızı ilk kez ölçüldükten sonra herhangi bir planlama yapılmaksızın 6 hafta sonra ikinci kez tekrar ölçülmüştür.

Bulgular: Altı haftalık düzenli core stabilizasyon egzersizleri yapan deney grubunun ortalama smaç hızının $58,66 \pm 10,58 \mathrm{~m} / \mathrm{s}^{\prime}$ den $69,50 \pm 9,66 \mathrm{~m} / \mathrm{s}^{\prime}$ ye $(\mathrm{p}<0,001)$ yükselmiş olduğu tespit edilmiştir. Ayrıca, çalışma başında deney ve control grupları arasında ortalama smaç hızı açısından anlamlı fark bulunmazken ( $\mathrm{p}=0,53)$, çalışma sonunda yapılan ölçümlerde deney grubunda ölçülen değerlerin $(69,50 \pm 9,66 \mathrm{~m} / \mathrm{s})$ kontrol grubundan $(64,10 \pm 9,57 \mathrm{~m} / \mathrm{s})$ anlamlı düzeyde yüksek olduğu $(\mathrm{p}=0,034)$ görülmüsstür.

Sonuç: Altı haftalık core stabilizasyon egzersizi programı, adölesan voleybolcularda smaç hızını arttırabilmektedir.

Anahtar Sözcükler: Voleybol, smaç hızı, kor stabilizasyon, smaç, egzersiz.

The Effect of Core Stabilization Exercises on Spike Velocity in Adolescent Volleyball Players

\begin{abstract}
Aim: This study was carried out to investigate the effect of regular core stabilization exercises on spike velocity in adolescent volleyball players.

Method: A total of 60 athletes between the ages of 15-18 who play professional volleyball in the same sports club voluntarily participated in the study. After measuring the spike velocity of the subject group consisting of 30 athletes with a radar gun, the athletes were included in the core stabilization exercise program and their spike velocity was measured again at the end of the 6-week program. Similarly, the spike speed of the
\end{abstract}

\footnotetext{
Özgün Araştırma Makalesi (Original Research Article)

Geliş / Received: 10.08.2021 \& Kabul / Accepted: 08.12.2021

DOI: https://doi.org/10.38079/iqusabder.979752

${ }^{*}$ Bu makale, Fzt. Umut Beycan'ın Üsküdar Üniversitesi 10385962 no'lu 2021 tarihli “Adölesan voleybol oyuncularında

kor stabilizasyon egzersizlerinin smaç hızına etkisi” isimli yüksek lisans tez çalışmasından türetilmiştir. (Tez

danışmanları: Tahsin Beyzadeoğlu, Kerem Yıldırım)

${ }_{* *}^{*}$ Uzm. Dr., Beyzadeoğlu Klinik, Ortopedi ve Travmatoloji, İstanbul, Türkiye, E-posta: drkeremyildirim@gmail.com

ORCID https://orcid.org/o000-0003-1624-64.38

*** Fzt., Fenerbahçe Spor Kulübü, Voleybol Şubesi, İstanbul, Türkiye, E-posta: ubeycan@ @otmail.com

ORCID https://orcid.org/0000-0001-6808-9070

${ }_{* * * * *}$ Prof. Dr., Haliç Üniversitesi, Sağlık Bilimleri Fakültesi, Fizyoterapi ve Rehabilitasyon Bölümü, İstanbul, Türkiye ; Beyzadeoğlu Klinik, Ortopedi ve Travmatoloji, İstanbul, Türkiye, E-posta: tbeyzade@superonline.com ORCID https://orcid.org/o000-0002-5836-4494
}

ETIK BILLDIRIM: Çalışma için Üsküdar Üniversitesi Girişimsel Olmayan Klinik Araştırmalar Etik Kurulu Başkanlığından 27/o3/2O2O tarihli, 61351342/2020-191 no'lu yazılı onay alınmıştır. 
control group consisting of 30 athletes was measured for the first time, and it was measured again after 6 weeks without any further exercise planning.

Results: The mean spike velocity of the subject group, who performed regular core stabilization exercises for six weeks, increased from $58.66 \pm 10.58 \mathrm{~m} / \mathrm{s}$ to $69.50 \pm 9.66 \mathrm{~m} / \mathrm{s}$ (p<0.001). Moreover, while there was no significant difference between the experimental and control groups in terms of average spiking speed at the beginning of the study $(\mathrm{p}=0.53)$, the values measured in the subject group $(69.50 \pm 9.66 \mathrm{~m} / \mathrm{s})$ at the end of the study were significantly higher than those of the control group $(64.10 \pm 9.57 \mathrm{~m} / \mathrm{s})(\mathrm{p}=0.034)$.

Conclusion: A six-week core stabilization exercise program may increase the spike velocity in adolescent volleyball players.

Keywords: Volleyball, spike velocity, core stabilization, spike, exercise.

\section{Giriş}

Voleybolda smaç, hücum organizasyonlarını sonlandırmada en sık kullanılan yöntemdir. Elit bir voleybolcu bir sezon boyunca 40.000 veya daha fazla smaç yapar ${ }^{1}$. Smaç hızı ise voleybol antrenmanlarının ve rekabetin ana faktörlerindendir².

Smacın safhaları; yaklaşma adımları, son adım, sıçrama, kol salınımı, topla temas ve düşüş olarak sıralanabilir3. Smaç için sıçrama sırasında mümkün olan en yüksek hareket açılığı̆yla kolları sallamak, momentumu ve yer tepkime kuvvetlerini arttırır. Alt ekstremite açılarının azaltılması ve üst gövdenin uzatılmasıyla bir karşı hareket oluşturulur. Önceden aktive edilmiş olan bu alt ekstremite kasları, bir gerilme ve kısalma döngüsü başlatır ve hızlanma mesafesini en uygun hale getirir. Ardından; dinamik kol salınımı, üst gövdenin yukarı kaldırılması, kalça, dizler ve ayak bileklerindeki ekstansiyon patlayıcı bir yukarı itiş meydana getirir. Bu yukarı itişin sonunda pelvis rotasyonu, topa mümkün olan en yüksek hızda smaç yapabilmek için, gövde rotasyonu, hızlı omuz fleksiyonu ve el bileği hareketleriyle uçuş fazı sırasında transfer edilen momentumu oluşturur 4 . Smaç hızı için, pelvis ve gövdede momentum oluşumu ve omuz internal rotasyonu, fleksiyonu ve el bileği ekstansiyonunda yüksek açısal hızlara geçişin önemli olduğu bilinmektedir 5 . Smaç vurma esneklik, kas kuvveti, koordinasyon ve nöromüsküler etkinlik gerektiren kompleks bir harekettir ve direnç antrenmanları ile göğüs/omuz ve gövde güç ve kuvvetinin arttırılması ile geliştirilebilir6. Birçok çalışmada, omuzun kuvvetini arttırmak için rotator cuff güçlendirici egzersiz programları önerilmiş olup, katılımcılar genellikle geleneksel dirençli egzersizleri tercih etmiştir7,8.

Tüm bunlara ek olarak core stabilizasyonu, gövdenin pelvis üzerindeki yerini ve hareketini en uygun hale getirir ve kas dayanıklılı̆̆ının en uygun bileşeni olarak kabul edilir. Core stabilizasyonun performans için faydalı olduğu, üst ve alt ekstremitelerin kuvvetlendirilmesine izin verdiği bilinmektedir9. Düşük core stabilizasyon seviyesi, bel ve diz yaralanmaları riskini

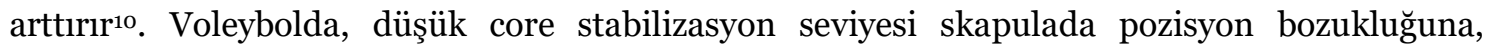
korakoid ağriya ve skapular diskineziye sebep olur ${ }^{11}$. Voleybol, omuz hareketlerine dayanan başüstü aktiviteleri içerdiğinden dolayı, verimli olabilmek için core stabilizasyonuna ihtiyaç duyar ${ }^{12}$.

Yukarıda verilmiş olan bilgilerden yola çıkılarak, belirli bir süre boyunca düzenli olarak yapılacak olan core stabilizasyonu antrenmanlarının smaç hızına olumlu yönde etki edeceği hipotezine ulaşılmış ve bu çalışma tasarlanmıştır. 


\section{Gereç ve Yöntem}

$\mathrm{Bu}$ çalışma randomize prospektif kontrollü bir çalışma olarak planlanmış ve Üsküdar Üniversitesi Girişimsel Olmayan Klinik Araştırmalar Etik Kurulu Başkanlı̆̆ı'ndan 27/03/2020 tarihli, 61351342/ 2020-191 no'lu yazılı onay alındıktan sonra çalışmaya başlanmıştır.

Çalışmaya 15-18 yaş aralığında, aynı spor kulübünde profesyonel voleybol oynayan erkek ve kadın toplam 60 sporcu gönüllü olarak katılmıştır. 15-18 yaş aralığındaki adölesan voleybol sporcuları arasından daha önce omuz ve bel cerrahisi geçirmemiş ve haftada en az 6 gün voleybol antrenmanı yapanlar çalışmaya dahil edilirken; dinlenme halindeyken ve smaç vururken ağrısı olan, kronik omuz ve bel problemi bulunan, öncesinde omuz cerrahisi geçiren ya da semptom veren nörolojik problemi bulunan sporcular çalışmaya dahil edilmemiştir.

Oyuncular mevki gözetmeksizin forma numaralarının tek ve çift oluşuna göre 2 gruba ayrılarak randomize edilmiştir. Forma numarası tek olanlar deney grubunu, çift olanlar ise kontrol grubunu oluşturmuştur. Deney grubunun smaç hızı ölçüldükten sonra sporcular core stabilizasyon egzersizi programına alınarak 6 haftalık çalışma sonunda smaç hızları tekrar ölçülmüştür. Kontrol grubunun ise smaç hızı ilk kez ölçüldükten sonra herhangi bir planlama yapılmaksızın 6 hafta sonra tekrar ölçülmüştür.

\section{Smaç Hızının Ölçülmesi}

Smaç hızı, radar tabanca (BUS-101911, Bushnell ${ }^{\circledR}$, California, ABD) kullanılarak ölçülmüştür. Oyunculardan smaç pozisyonu alması istenerek cihaz topu firlatan sporcunun karşısına yerleştirilmiş, oyuncudan mümkün olan en yüksek hızda smaç yapması istenmiştir. Toplam 3 ölçüm yapılarak, ölçümlerin içindeki en yüksek hız radar cihazının ekranından okunarak kaydedilmiştir. Ölçümler arasında dinlenme süresi belirlenmemiş, oyunculardan hazır olduklarında smaç yapmaları istenmiştir.

\section{Egzersiz Programı}

Araştırmaya dahil edilen oyunculara, haftalık egzersiz programları (Tablo 1) tarif edilip gösterildikten sonra uygulamaya başlanmış, egzersizlere haftada 3 gün olacak şekilde, toplam 6 hafta boyunca devam edilmiştir.

Tablo 1. Core egzersiz programi ${ }^{13}$

\begin{tabular}{|c|c|c|c|}
\hline & 1.-2. Haftalar & $\begin{array}{l}\text { 3.-4. } \\
\text { Haftalar }\end{array}$ & 5.-6. Haftalar \\
\hline $\begin{array}{l}\text { Mekik } \\
\text { (Sit Up 1) }\end{array}$ & 40 saniye $x 3$ set & $\begin{array}{l}50 \text { saniye } \times 3 \\
\text { set }\end{array}$ & 60 saniye $\times 3$ set \\
\hline $\begin{array}{l}\text { Çapraz Mekik } \\
\text { (Sit Up 2) }\end{array}$ & 40 saniye $\times 3$ set & $\begin{array}{l}50 \text { saniye } \times 3 \\
\text { set }\end{array}$ & $\begin{array}{l}25 \text { saniye x } 3 \text { set } \\
\text { (sırasıyla sağ ve sol ayakları kaldırarak) }\end{array}$ \\
\hline $\begin{array}{l}\text { Ters Mekik } \\
\text { (Back Extension 1) }\end{array}$ & 40 saniye $\times 3$ set & $\begin{array}{l}40 \text { saniye } \times 4 \\
\text { set }\end{array}$ & 40 saniye $x 4$ set \\
\hline $\begin{array}{l}\text { Çapraz Ters Mekik (Back } \\
\text { Extension 2) }\end{array}$ & - & $\begin{array}{l}50 \text { saniye } \times 2 \\
\text { set }\end{array}$ & 50 saniye $\times 2$ set \\
\hline $\begin{array}{l}\text { Öne Plank } \\
\text { (Front Plank) }\end{array}$ & $\begin{array}{l}60 \text { saniye } \\
\text { izometrik } \\
2 \text { tekrar x } 1 \text { set }\end{array}$ & $\begin{array}{l}60 \text { saniye } \\
\text { izometrik } \\
3 \text { tekrar x } 1 \text { set }\end{array}$ & $\begin{array}{l}\text { 10 saniye izometrik } \\
3 \text { tekrar x } 1 \text { set } \\
\text { (sırasıyla sağ kol-sol kol-sağ ayak-sol ayak } \\
\text { kaldırarak) }\end{array}$ \\
\hline $\begin{array}{l}\text { Köprüi } \\
\text { (Back Bridge) }\end{array}$ & 60 saniye $\times 2$ set & $\begin{array}{l}\text { 6o saniye } \times 3 \\
\text { set }\end{array}$ & 80 saniye $\times 3$ set \\
\hline $\begin{array}{l}\text { Dörtlü Egzersiz } \\
\text { (Quadpured Exercise) }\end{array}$ & $\begin{array}{l}\text { 10 saniye } \\
\text { izometrik } \\
3 \text { tekrar x } 1 \text { set }\end{array}$ & $\begin{array}{l}\text { 10 saniye } \\
\text { izometrik } \\
\text { 4 tekrar x 1 set }\end{array}$ & $\begin{array}{l}\text { 10 saniye izometrik } \\
5 \text { tekrar x } 1 \text { set }\end{array}$ \\
\hline $\begin{array}{l}\text { Sağ ve Sol Plank } \\
\text { (Side Bridge) }\end{array}$ & $\begin{array}{l}\text { 30 saniye } \\
\text { izometrik } \\
1 \text { tekrar x } 1 \text { set }\end{array}$ & $\begin{array}{l}\text { 30 saniye } \\
\text { izometrik } \\
2 \text { tekrar x } 1 \text { set }\end{array}$ & $\begin{array}{l}\text { 40 saniye izometrik } \\
2 \text { tekrar x } 1 \text { set }\end{array}$ \\
\hline
\end{tabular}




\section{Verilerin Analizi}

İstatistiksel analizler IBM SPSS 21 paket programı ile yapılmıştır. Verilerin normal dağılıma uygunluğunun incelenmesinde Shapiro-Wilk testi kullanılmıs ve önem düzeyi o,o5'ten yüksek olanların normal dağılım gösterdiği; düşük olanların ise normal dağılmadığg kabul edilmiştir. Normal dağılım gösteren değişkenlerin analizinde bağımsız gruplar t testi kullanılmıştır. Sonuçlar, 'ortalama \pm standart sapma' olarak gösterilmiştir. Normal dağılım gösteren değişkenlerin grup içindeki kıyaslanmasında ise bağımlı-eşlenmiş gruplar t testi kullanılmış, $\mathrm{p}<0,05$ anlamlı olarak kabul edilmiştir.

\section{Bulgular}

Çalışmaya toplamda 60 sporcu katılmış olup ve sporcular randomize olarak iki gruba ayrılmışlardır. Deney ve kontrol gruplarının her biri 24 kadın, 6 erkek olmak üzere toplam 30'ar sporcudan oluşturulmuştur. Katılımcı sporcuların demografik bilgileri Tablo 2'de verilmiştir.

Tablo 2. Deney ve kontrol grubu katılımcıların demografik özellikleri

\begin{tabular}{|l|c|c|c|}
\hline \multicolumn{2}{|c}{ Oeney Grubu (n=30) } & Ort \pm SS & p \\
\hline \multicolumn{2}{|c|}{ Ort } & $16,17 \pm 0,95$ & 0,394 \\
\hline Yaş & $15,97 \pm 0,85$ & & 0,179 \\
\hline Ăğırlık (kg) & $65,93 \pm 13,04$ & $69,73 \pm 8,01$ & 0,051 \\
\hline Boy (cm) & $177,90 \pm 11,35$ & $183,43 \pm 8,96$ & \\
\hline
\end{tabular}

n: Katılımcı sayısı, Ort: Ortalama, SS: Standart sapma

Core stabilizasyonu antrenmanları öncesinde yapılan ilk ölçümlerde kontrol grubu ile deney grubunun ortalama smaç hızları arasında anlamlı bir fark tespit edilmemiştir (p>0,05) (Tablo 3).

Tablo 3. Deney ve kontrol grubu katılımcılarının egzersiz programı öncesi smaç hızlarının karşılaştırılması

\begin{tabular}{|l|c|c|c|}
\hline \multicolumn{3}{|c|}{ Deney Grubu (n=30) } & Ort \pm SS \\
\hline $\begin{array}{l}\text { Ort } \pm \text { SS } \\
(\mathrm{m} / \mathrm{s})\end{array}$ & $58,66 \pm 10,58$ & $63,80 \pm 9,48$ & 0,053 \\
\hline
\end{tabular}

n: Katılımcı sayısı, Ort: Ortalama, SS: Standart sapma

Deney grubunda yer alan sporcuların smaç hızlarının, 6 haftalık egzersiz programından sonra yapılan ikinci ölçümlerde anlamlı düzeyde arttığ $(\mathrm{p}<0,001)$, kontrol grubuna yapılan ikinci ölçümlerde ise, smaç hızında anlamlı bir değişim olmadığı görülmüsştür (Tablo 4). Ayrıca, son ölçümlerde deney grubunda yer alan sporcuların smaç hızlarının, kontrol grubunda yer alan sporculara göre anlamlı düzeyde yüksek olduğu görülmüştür ( $p=0,034)$ (Tablo 5). 
Tablo 4. Deney ve kontrol grubu katılımcılarının egzersiz programı öncesi ve sonrası smaç hızlarının karşılaştırılması

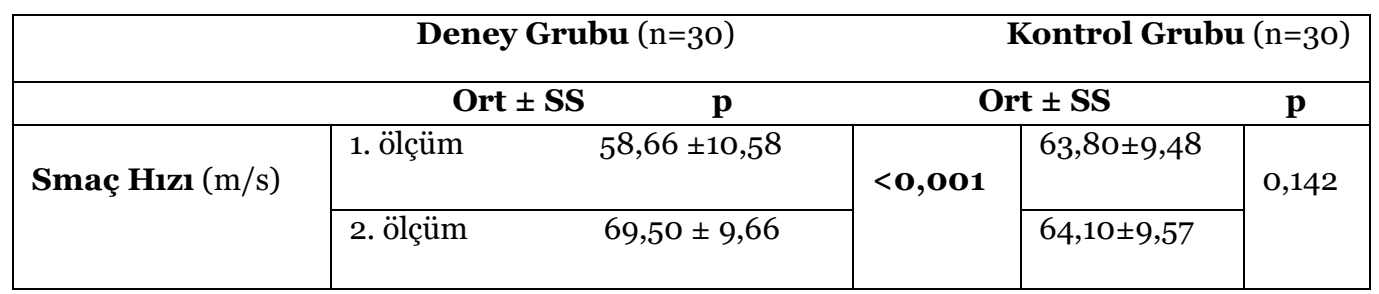

n: Katılımcı sayısı, Ort: Ortalama, SS: Standart sapma

Tablo 5. Deney ve kontrol grubu katılımcılarının egzersiz programı sonrası smaç hızlarının karşılaştırılması

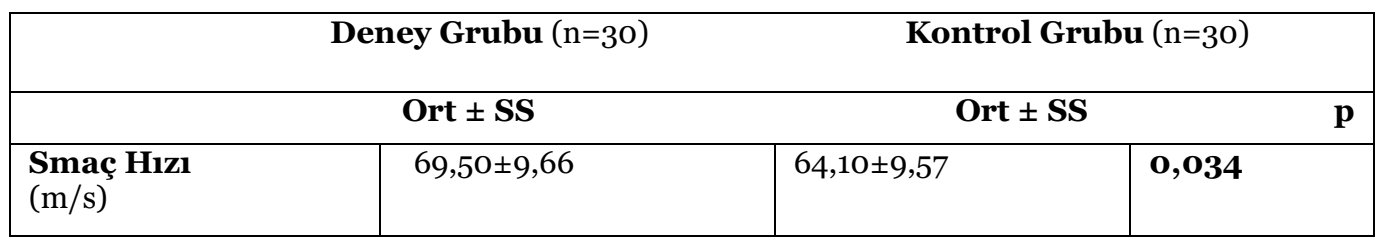

n: Katılımcı sayısı, Ort: Ortalama, SS: Standart sapma

\section{Tartışma}

$\mathrm{Bu}$ çalışmada elde edilen en önemli bulgu, 6 haftalık düzenli core stabilizasyon egzersizi uygulamasının adölesan voleybolcularda smaç hızını arttırabileceğidir.

Voleybolda smaç vuruşu, takımların doğrudan sayı kazanabildiği ve rakibin karşılamakta problem yaşayabileceği bir hücum tekniğidir. Hiç şüphesiz, voleybolda takımların hücum etkinliği için smaç vuruşu belirleyici bir unsurdur ${ }^{14,15}$. Yaklaşmayı takiben dikey sıçramayla yapılan smaçın en önemli unsurlarından birisi, topu mümkün olan en yüksek hızda vurmaktır ${ }^{16}$. Yapılan bir çalışmada, elit bir voleybol oyuncusunun, bir voleybol sezonu boyunca binlerce kez servis atışı ve smaç vuruşu gerçekleştirdiği gösterilmiştir ${ }^{17}$.

Core antrenmanların rehabilitasyon amaçlı uygulamaları ile ilgili oldukça fazla bilimsel bulguya rastlanırken, performansa ilişkin antrenman uygulamaları daha azdır. Core antrenmanlarının sporcular açısından çoğunlukla, başlıca motorik özellikleri geliştirici antrenmanların temelini oluşturmaması, genellikle tedavi edici, iyileştirici, koruyucu ve yardımcı antrenmanlar olarak ana antrenmanların yanında uygulanışı buna sebep olarak görülebilir. Neredeyse tüm spor dallarında ve egzersiz yapan bireylerin antrenman programlarında core antrenmanı uygulamalarının dahil edilmesinin faydalı olacağı düşünülmektedir ${ }^{18}$.

Literatürde farklı spor branşlarında core stabilizasyon egzersizlerinin top firlatma üzerine etkileri incelenmiştir. Manchado ve ark., 30 profesyonel hentbol oyuncusu üzerinde yaptıkları çalışmada, 10 haftalık core stabilizasyon egzersizlerinin top fırlatma hızı üzerine etkilerini incelemişler ve sonuç olarak, bu egzersizleri yapan grubun top fırlatma hızının, sadece hentbol antrenmanı yapan gruba kıyasla anlamlı düzeyde arttığını bildirmişlerdir ${ }^{19}$.

Saeterbakken ve ark., 28 profesyonel kadın hentbol oyuncusu üzerinde yaptıkları çalışmada, deney ve kontrol grubunun çalışma öncesi ölçülen top firlatma hızları arasında anlamlı bir fark bulunmamasına rağmen; 6 haftalık core stabilizasyon egzersizlerinin, deney grubunun top 
fırlatma hızını anlamlı derecede arttırdığı sonucuna ulaşmışlardır²0. Bu çalışmanın dizaynı ve sonucu, bizim yaptığımız çalışmayla benzerlik göstermektedir.

Bir çalışmada voleyboldaki smaç hareketi incelenmiş, hareket temelinin hentboldaki şut tekniğine yakın olduğu rapor edilmiştir. Bu sebeple, düzenli yapılan kor antrenmanların voleybolda smaç vuruşunun hızına olumlu etki edeceği varsayımında bulunulmaktadır ${ }^{21}$. Bizim çalışmamızın sonucu da bu varsayımı doğru çıkarmaktadır.

2018 yılında yayınlanan ve 20 kadın hentbol oyuncusu üzerinde yapılan bir çalışmada; oyuncular randomize olarak iki gruba ayrılmışlar ve deney grubuna, hentbol antrenmanına ek olarak 6 haftalık core stabilizasyon egzersizi programı uygulanmıştır. Çalışmanın sonucunda, her iki grubun da top firlatma hızları artmış fakat deney grubuyla kontrol grubu arasında anlamlı bir fark saptanmamıştır ${ }^{22}$. Bizim çalışmamızla kıyasladığımızda, her iki grubun da top firlatma hızlarının artmış olması, çalışmamızın sonucu ile uyuşmamakla birlikte; deney grubunun top firlatma hızının artmış olması çalışmamızın sonucu ile benzerlik göstermektedir.

Sever ve ark., 2017 yılında yayınladıkları bir çalışmada, core stabilizasyon egzersizlerinin tenis oyunundaki servis hızına etkisini incelemişlerdir. 24 erkek tenis oyuncusunun dahil edildiği çalışma sonucunda, core stabilizasyon egzersizlerinin, servis hızını anlamlı derecede arttırdığı bulunmuştur 23.

Zingaro, 2008 yılında yaptığı bir çalışmada core kas kuvveti ile tenis oyuncularının servis hızları arasındaki ilişkiyi araştırmıştır. 11 kadın ve 6 erkek gönüllü denek üzerinde yapılan çalışmanın sonucunda; kadın tenis oyuncularının core kas kuvveti ile servis hızı arasında anlamlı bir ilişki tespit edilirken, erkek tenis oyuncularında böyle bir ilişki tespit edilmemiştir. Zingaro buna sebep olarak, erkek tenis oyuncularının üst ekstremite kas kuvvetlerinin, core kas kuvvetini kompanse edebileceğini söylemiştir. Daha sağlıklı bir değerlendirme için erkek katılımcı sayısının daha fazla olduğu bir araştırma yapılmasını da önermiştir 24.

Yapılan başka bir çalışmada, 12 haftalık terapi topu antrenman programı ile genç beyzbolcularda squat ve bench press skorları değişmezken, rotasyonel kuvvet ve vuruş hızı core egzersiz grubunda daha fazla artmıştır25.

Başka bir çalışmada ise kolej beyzbol takımına açık ve kapalı zincir egzersizlerden oluşan antrenman programı uygulanmıştır. Bir grup ekstra core stabilizasyon egzersizleri yapmıştır. Yazarlar 6 haftalık programın core stabilizasyon yapan grupta firlatma hızını daha olumlu etkilediğini belirtmişlerdir ${ }^{26}$.

Atıcı pozisyonunda oynayan 14 beyzbol oyuncusu üzerinde yapılan başka bir çalışmada, oyuncuların top atış hızı ölçülmüş ve 6 haftalık core stabilizasyon egzersizi programından sonra ölçümler tekrarlanmıştır. Son ölçümlerde top hızının anlamlı derecede artmış olduğu bildirilmiştir. Yazarlar beyzbolda topa vurma eyleminin sadece kolu değil, alt ekstremite ve gövdeyi de içeren komplike bir hareket olduğunu ve gövde kaslarının kuvvetlendirilmesinin sadece yaralanmaları önlemek veya tedavi etmek amaçlı değil, aynı zamanda performansı arttırmak için de gerekli olduğunu belirtmişlerdir27.

2017 yılında yayınlanan, 14-15 yaş voleybol kız öğrencilerinin katıldığı bir çalışmada, 12 haftalık pilates mat egzersizlerinin bazı biyomotor özellikler ve teknik performans üzerine etkileri incelenmiş ve sonuç olarak, smaç hızının deney grubunda anlamlı olarak arttığı tespit edilmiştir ${ }^{28}$. Bu çalışmada uygulanan egzersiz programı tam olarak core stabilizasyon egzersizleri olmasa da bu çalışmadaki bazı egzersizleri içermektedir ve bu bakımdan çalışmamızla benzerlik göstermektedir. 
El bileği ve omuz eklemi izokinetik kuvveti ile servis ve smaç hızının ilişkisinin değerlendirildiği ve 34 elit kadın voleybolcunun dahil edildiği bir çalışmada, el bileği ve omuz izokinetik kuvveti ile servis ve smaç hızları arasında anlamlı bir ilişki tespit edilmemiştir. Voleybol oyununda üst ekstremite kas kuvvetiyle servis ve smaç hızı arasında anlamlı bir ilişki olduğu bilinmesine rağmen; bu sonuç sadece üst ekstremite kas kuvveti ile servis atış ve smaç vuruş hızının artmadığını, üst ekstremiteyle beraber gövde kaslarının da etkisiyle servis atış ve smaç hızının arttırılabileceğini göstermiştir. Bu sonuçla beraber, voleybol oyununda servis atış ve smaç vuruş hızlarının arttırılabilmesi için, üst ekstremiteyle beraber gövde kaslarının da güçlendirilmesi tavsiye edilmiştir 29 .

Agopyan ve arkadaşları, 8 haftalık terabant egzersizlerinin adölesan voleybolcularda smaç hızı, sıçrama yüksekliği ve üst ektremitenin performans parametlerine etkisini araştırmışlardır. 20 kadın voleybol oyuncusunun dahil edildiği çalışma sonucunda; üst ekstremite, alt ekstremite ve gövde egzersizlerini içeren terabant egzersiz grubunda smaç hızının, sadece voleybol antrenmanı yapan diğer gruba göre anlamlı derecede arttığı bildirilmiştir. Bu çalışma, Aka'nın belirttiği ${ }^{29}$ ve daha hızlı bir smaç için gövde kaslarının da güçlendirilmesi gerektiği sonucunu desteklemektedir ${ }^{6}$.

24 kadın voleybolcunun katıldığı ve voleybolcularda üst ekstremiteye uygulanan 8 haftalık terabant egzersizlerinin servis ve smaç hızına etkisini araştıran bir çalışmada ise, sadece üst ekstemiteye uygulanan terabant egzersizlerinin antrenman grubunda servis ve smaç hızını anlamlı derecede arttırdığı; kontrol grubunda ise servis hızının artmamasına rağmen smaç hızının arttığı bildirilmiştir. Bu çalışma da sadece üst ekstremite kas kuvvetinin, hızlı smaç yapmada yeterli olmadığını göstermektedir30.

Voleybolda smaç hızını etkileyen faktörlerin incelendiği bir çalışmada, dominant taraf omzun internal rotatör kasları ve dominant taraf el bileğinin hem fleksör hem de ekstansör kaslarının kuvvetiyle smaç hızı arasında anlamlı bir ilişki saptanmıştır. Aynı çalışmada smaç hızı ile oyuncuların sıçrama yüksekliği arasında da doğru orantı olduğu bildirilmiştir31.

Voleybolda kuvvet-hız ilişkisinin incelendiği başka bir çalışmada sıçrama, hızlı koşu ve bench press hareketinin voleybolcularda servis ve smaç hızı üzerine etkileri araştırılmıştır. 22 elit erkek voleybolcunun dahil edildiği çalışmanın sonucunda sıçrama, hızlı koşu ve bench presste daha başarılı olan sporcuların hem servis hem de smaç hızlarının daha hızlı olduğu rapor edilmiştir. Yazarlar bu 3 faktörün servis ve smaç hızında \%20-\%36 oranında etkili olduğunu, bu etkinin önemli olmakla birlikte, bunların dışında çok sayıda farklı faktörün servis ve smaç hızına etki ettiğini bildirmişlerdir ${ }^{2}$.

Çalışmamızın bazı limitasyonları bulunmaktadır. Bunlardan en önemlileri, çalışma popülasyonunun birey sayısı açısından sınırlı olması ve cinsiyet açısından homojen olmamasıdır. Bu sorunu ortaya çıkaran başlıca sebep, çalışmamızın tek merkezli olması ve bu merkeze bağlı lisanslı sporcu topluluğunun hem sayı açısından sınırlı olması hem de kayıtlı tüm sporcular arasında cinsiyet açısından bir homojenite bulunmamasıdır. Bu açıdan bakıldığında çalışma gruplarının katılımcı sayısının daha yüksek, cinsiyet dağılımının daha homojen olduğu daha büyük çalışmalar tasarlanabilir. Ancak, her ne kadar örneklem büyüklüğü düşük gibi görünse de, deney grubunun smaç hızındaki değişim baz alınarak yapılan ve 0,05 güven aralığına sahip posthoc analizde çalışmamızın istatistiksel gücü \%98,6 olarak tespit edilmiştir.

Ayrıca, bu çalışmada sadece 6 haftalık kısa bir programın erken dönem sonuçlarından sadece smaç hızı değişikliği değerlendirilmiştir. Buna alternatif olarak egzersiz programı tüm bir sezona yayılarak, sezon başı ve sezon sonu smaç hızlarının karşılaştırılacağı ve ek olarak söz konusu 
egzersiz programının tüm bir sezon boyunca gelişecek sakatlanma oranına etkisinin inceleneceği biçimde tasarlanmış çalışmalar da yapılabilir.

\section{Sonuç}

Altı haftalık core stabilizasyon egzersizi programı, adölesan voleybolcularda smaç hızını arttırabilmektedir.

\section{Çıkar Çatışması}

Yazarların beyan edilebilecek herhangi bir çıkar çatışmaları bulunmamaktadır.

\section{Etik Kurul Onayı}

Bu çalışma ile ilgili olarak Üsküdar Üniversitesi Girişimsel Olmayan Klinik Araştırmalar Etik Kurulu Başkanlığı'ndan 27/03/2020 tarihli, 61351342/ 2020-191 no'lu onay belgesi alınmıştır.

\section{KAYNAKLAR}

1. Kugler A, Krüger-Franke M, Reininger S, Trouillier HH, Rosemeyer B. Muscular imbalance and shoulder pain in volleyball attackers. Br J Sports Med. 1996;30(3):256-259. doi:10.1136/bjsm.30.3.256.

2. Powers ME. Vertical jump training for volleyball. Strength and Conditioning. 1996;18:1823.

3. Öz E. Voleybolda smaçın biyomekaniksel incelenmesi. In: 5. Antrenman Bilimi Kongresi; 2013; Ankara, Türkiye.

4. Fuchs PX, Mitteregger J, Hoelbling D et al. Relationship between general jump types and spike jump performance in elite female and male volleyball players. Applied Sciences. 2021;11(3):1105.

5. Caruso JF, Daily JS, Olson NM. Anthropometry and gender influences on the arm swing's contribution to vertical jump heights. Isokinet Exerc Sci. 2012;20(1):23-29.

6. Agopyan A, Özbar N, Özdemir SN. Effects of 8-week thera-band training on spike speed, jump height and speed of upper limb performance of young female volleyball players. International Journal of Applied Exercise Physiology. 2018;7(1):63- 76.

7. Mascarin NC, de Lira CAB, Vancini RL, da Silva AC, Andrade MS. The effects of preventive rubber band training on shoulder joint imbalance and throwing performance in handball players: a randomized and prospective study. $J$ Bodyw Mov Ther. 2017;21(4):1017-1023. doi:10.1016/j.jbmt.2017.01.003.

8. Labat G, Hey W. Can an elastic band resistance training program increase muscular strength. Kentucky Association of Health, physical education. Recreation and Dance Journal. 2017;55(1):33-38.

9. Willardson JM. Core stability training: Applications to sports conditioning programs. $J$ Strength Cond Res. 2007;21(3):979-985. doi:10.1519/R-20255.1.

10. Borghuis J, Hof AL, Lemmink KA. The importance of sensory-motor control in providing core stability: implications for measurement and training. Sports Med. 2008;38(11):893916. doi:10.2165/00007256-200838110-00002. 
11. Reeser JC, Joy EA, Porucznik CA, Berg RL, Colliver EB, Willick SE. Risk factors for volleyball-related shoulder pain and dysfunction. $P M R$. 2010;2(1):27-36. doi:10.1016/j.pmrj.2009.11.010.

12. Zandi S, Rajabi R, Minoonejad H, Mohseni-Bandpei M. Core muscular endurance in volleyball players with anterior shoulder instability and asymptomatic players. Med. Dello Sport. 2018;71:96-106.

13. Bagherian S, Ghasempoor K, Rahnama N, Wikstrom EA. The effect of core stability training on functional movement patterns in college athletes. J Sport Rehabil. 2019;28(5):444-449. doi:10.1123/jsr.2017-0107.

14. Coleman SG, Benham AS, Northcott SR. A three-dimensional cinematographical analysis of the volleyball spike. J Sports Sci. 1993;11(4):295-302. doi:10.1080/02640419308729999.

15. Ciccarone G, Stabile ME, Mirarchi AR. Evaluation of Jumping Capacities in High-level Basket and Volley Athletes. In: Xxe Congrès International de Médecine du Sport; 2000;145:332.

16. Rokito AS, Jobe FW, Pink MM, Perry J, Brault J. Electromyographic analysis of shoulder function during the volleyball serve and spike. $J$ Shoulder Elbow Surg. 1998;7(3):256-263. doi:10.1016/s1058-2746(98)90054-4.

17. Jonathan JR, Ronald B. Volleyball Handbook of Sport Medicine and Science. 1st ed. Hong Kong: Blackwell Publishing; 2003.

18. Egesoy H, Alptekin A, Yapıcı A. Sporda Kor Egzersizler. International Journal of Contemporary Educational Studies. 2018;4(1):10-21.

19. Manchado C, García-Ruiz J, Cortell-Tormo JM, Tortosa-Martínez J. Effect of core training on male handball players' throwing velocity. J Hum Kinet. 2017;56:177-185. doi:10.1515/hukin-2017-0035.

20. Saeterbakken AH, van den Tillaar R, Seiler S. Effect of core stability training on throwing velocity in female handball players. $J$ Strength Cond Res. 2011;25(3):712-718. doi:10.1519/JSC.obo13e3181cc227e.

21. Şatıroğlu S, Arslan E, Atak M. Voleybolda Core Antrenman Uygulamaları. In: 5. Antrenman Bilimi Kongresi; 2013; Ankara, Türkiye.

22. Kuhn L, Weberruß H, Horstmann T. Effects of core stability training on throwing velocity and core strength in female handball players. J Sports Med Phys Fitness. 2019;59(9):14791486. doi:10.23736/Soo22-4707.18.09295-2.

23. Sever O, Kır R, Yaman M. The impact of periodized core training program on accurate service velocity of male tennis players aged 11-13. Journal of Human Sciences. 2017;14(3):3022-3030.

24. Zingaro RE. A Correlation Between Core Strength and Serve Velocity in Collegiate Tennis Players [master's thesis]. Pennsylvania, California, USA: California University of Pennsylvania; 2008.

25. Szymanski DJ, Szymanski JM, Bradford TJ, Schade RL, Pascoe DD. Effect of twelve weeks of medicine ball training on high school baseball players. $J$ Strength Cond Res. 2007;21(3):894-901. doi:10.1519/R-18415.1. 
26. Lust KR, Sandrey MA, Bulger SM, Wilder N. The effects of 6-week training programs on throwing accuracy, proprioception, and core endurance in baseball. $J$ Sport Rehabil. 2009;18(3):407-426. doi:10.1123/jsr.18.3.407.

27. Lee HK, Jung DE, Lee JC. The effects of core strengthening training on baseball throwing. $J$ Int Acad Phys Ther Res. 2016;7(1):965-971.

28. Demir İC, Çilli M. 12 haftalık pilates mat egzersizinin 14-15 yaş voleybol kız öğrencilerinin bazı biyomotor özellikler ve teknik performans üzerine etkilerinin incelenmesi. Online Türk Sağlık Bilimleri Dergisi. 2018;3(1):1-13.

29. Aka H. Elit Kadın Voleybolcularda El Bilek ve Omuz Eklemi İzokinetik Kuvveti ile Servis Atış ve Smaç Vuruş Hızı İlişkisi [doktora tezi]. Ankara, Türkiye: Gazi Üniversitesi, Sağlık Bilimleri Enstitüsü; 2018.

30. Ağıllı S. Voleybolcularda Üst Ekstremiteye Uygulanan 8 Haftalık Terabant Egzersizlerinin Servis ve Smaç Hızına Etkisi [yüksek lisans tezi]. Niğde, Türkiye: Niğde Ömer Halisdemir Üniversitesi, Sosyal Bilimler Enstitüsü, Beden Eğitimi ve Spor Anabilim Dalı; 2020.

31. Forthomme B, Croisier JL, Ciccarone G, Crielaard JM, Cloes M. Factors correlated with volleyball spike velocity. Am J Sports Med. 2005;33(10):1513-1519. doi:10.1177/0363546505274935.

32. Baena-Raya A, Soriano-Maldonado A, Rodríguez-Pérez MA, et al. The force-velocity profile as determinant of spike and serve ball speed in top-level male volleyball players. PLoS One. 2021;16(4):e0249612. doi:10.1371/journal.pone.0249612. 